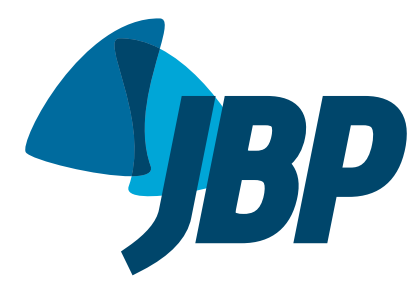

1. Programa de Pós-Graduação em Ciências Médicas, Universidade Federal do Rio Grande do Sul - UFRGS Porto Alegre (RS) Brasil.

2. Pesquisa Básica e Investigações Avançadas em Neurologia, Centro de Pesquisa Experimental, Hospital de Clínicas de Porto Alegre, Porto Alegre (RS) Brasil.

3. Universidade do Vale do Rio dos Sinos UNISINOS - São Leopoldo (RS) Brasil.

4. Unidade de Terapia Intensiva, Hospital Cristo Redentor, Porto Alegre (RS) Brasil.

5. Curso de Fisioterapia, Programa de Pós-Graduação em Reabilitação e Inclusão e Biociências e Reabilitação, Centro Universitário Metodista - IPA Porto Alegre (RS) Brasil.

6. Divisão de Neurologia, Hospital de Clínicas de Porto Alegre, Porto Alegre (RS) Brasil.

Submitted: 04 August 2016. Accepted: 18 November 2016.

Study carried out in the Unidade de Terapia Intensiva, Hospital Cristo Redentor, Porto Alegre (RS) Brasil.

\section{Simple motor tasks independently predict extubation failure in critically ill neurological patients}

\author{
Fernanda Machado Kutchak $k^{1,2,3,4}$, Marcelo de Mello Rieder $r^{1,2,4}$, \\ Josué Almeida Victorino ${ }^{1,4}$, Carla Meneguzzi ${ }^{4}$, Karla Poersch ${ }^{3}$, \\ Luiz Alberto Forgiarini Junior ${ }^{5}$, Marino Muxfeldt Bianchin ${ }^{1,2,6}$
}

\begin{abstract}
Objective: To evaluate the usefulness of simple motor tasks such as hand grasping and tongue protrusion as predictors of extubation failure in critically ill neurological patients. Methods: This was a prospective cohort study conducted in the neurological ICU of a tertiary care hospital in the city of Porto Alegre, Brazil. Adult patients who had been intubated for neurological reasons and were eligible for weaning were included in the study. The ability of patients to perform simple motor tasks such as hand grasping and tongue protrusion was evaluated as a predictor of extubation failure. Data regarding duration of mechanical ventilation, length of ICU stay, length of hospital stay, mortality, and incidence of ventilator-associated pneumonia were collected. Results: A total of 132 intubated patients who had been receiving mechanical ventilation for at least $24 \mathrm{~h}$ and who passed a spontaneous breathing trial were included in the analysis. Logistic regression showed that patient inability to grasp the hand of the examiner (relative risk $=1.57 ; 95 \%$ $\mathrm{Cl}: 1.01-2.44 ; \mathrm{p}<0.045$ ) and protrude the tongue (relative risk $=6.84 ; 95 \% \mathrm{Cl}: 2.49-18.8$; $\mathrm{p}<0.001)$ were independent risk factors for extubation failure. Acute Physiology and Chronic Health Evaluation II scores $(p=0.02)$, Glasgow Coma Scale scores at extubation $(p<0.001)$, eye opening response $(p=0.001)$, $\operatorname{MIP}(p<0.001), \operatorname{MEP}(p=0.006)$, and the rapid shallow breathing index $(p=0.03)$ were significantly different between the failed extubation and successful extubation groups. Conclusions: The inability to follow simple motor commands is predictive of extubation failure in critically ill neurological patients. Hand grasping and tongue protrusion on command might be quick and easy bedside tests to identify neurocritical care patients who are candidates for extubation.
\end{abstract}

Keywords: Ventilator weaning; Airway extubation/adverse effects; Critical care; Neurosurgery.

\section{INTRODUCTION}

Extubation failure and need for reintubation occur in $2-25 \%$ of mechanically ventilated patients in the ICU. These rates vary depending on the type of patient and the weaning protocol used. ${ }^{(1)}$ In the last decades, several studies have focused on predictors of successful ventilator weaning. ${ }^{(2,3)}$ More recently, several authors have emphasized the need for better predictors of extubation outcome in patients with neurological injuries. ${ }^{(4-7)}$ Predictors of extubation success in critically ill neurological patients range from subjective signs to more complex assessments that are mainly based on objective respiratory parameters. ${ }^{(2,8,9)}$ However, there is no consensus regarding the best predictors of successful weaning and extubation in such patients, and results have varied across studies, ${ }^{(8,10)}$ certain predictors having failed to guide the decision making process. Parameters such as being able to stick out the tongue, having a gag reflex, and being able to follow specific commands have been investigated as more reliable tools to assess the level of consciousness and the ability to protect the airway. ${ }^{(4-7,9,11,12)}$ However, in a neurological critical care setting, adequate parameters for extubation have yet to be defined.
The objective of the present study was to evaluate the usefulness of simple motor tasks such as hand grasping and tongue protrusion as predictors of extubation failure in critically ill neurological patients. This was done in an attempt to provide simple clinical tools to identify candidates for extubation in the neurological ICU.

\section{METHODS}

This was a prospective cohort study conducted in the ICU of Hospital Cristo Redentor, in the city of Porto Alegre, Brazil, between October of 2010 and December of 2011. Hospital Cristo Redentor is a 290-bed regional referral center for trauma care and neurosurgery, approximately 300 patients being referred to the hospital every day. The ICU is a closed unit comprising 29 beds, care being provided by physicians in routine practice and on duty, as well as by five physiotherapists working during the day shift.

The inclusion criteria were as follows: being an ICU patient; having been on mechanical ventilation for $\geq 24$ $h$; being $\geq 18$ years of age; having a neurological disorder

Correspondence to:

Fernanda Kutchak. Unidade de Terapia Intensiva, Hospital Cristo Redentor, Rua Domingos Rubbo, 20, CEP 91040-000, Porto Alegre, RS, Brasil.

Tel.: 5551 3286-4948. E-mail: fernandakutchak@terra.com.br

Financial support: None. 
or brain injury; and being eligible for weaning. The exclusion criteria were as follows: having a spinal cord injury; having thoracic or abdominal trauma; having a peripheral neuromuscular disorder; and being a patient whose legal guardian(s) or caregiver(s) did not give written informed consent. Figure 1 shows a schematic diagram of patient selection. The study was approved by the local research ethics committee and was conducted in accordance with the provisions of the Declaration of Helsinki. Written informed consent was obtained from the legal guardians or caregivers of all participating patients.

All participating patients had been on mechanical ventilation (Evita 4; Drägerwerk AG \& Co. KGaA, Lübeck, Germany; or Servo-i; MAQUET Holding B.V. \& Co. KG, Rastatt, Germany) for $\geq 24 \mathrm{~h}$. The criteria for extubation were as follows: adequate oxygenation $\left(\mathrm{PaO}_{2}>60\right.$ Torr $\left[8 \mathrm{KPa}\right.$ ]; $\mathrm{FiO}_{2}<0.4$; positive end-expiratory pressure $<6$ Torr $[0.8 \mathrm{KPa}]$, and $\mathrm{PaO}_{2} / \mathrm{FiO}_{2}$ $>150)$; cardiovascular stability $(\mathrm{HR}<130 \mathrm{bpm}$ and mean blood pressure $>60$ Torr $[8 \mathrm{KPa}]$, with minimal or no use of vasopressors); axillary temperature < $37.5^{\circ} \mathrm{C}$; hemoglobin level $>8 \mathrm{~g} / \mathrm{dL}$; Glasgow Coma

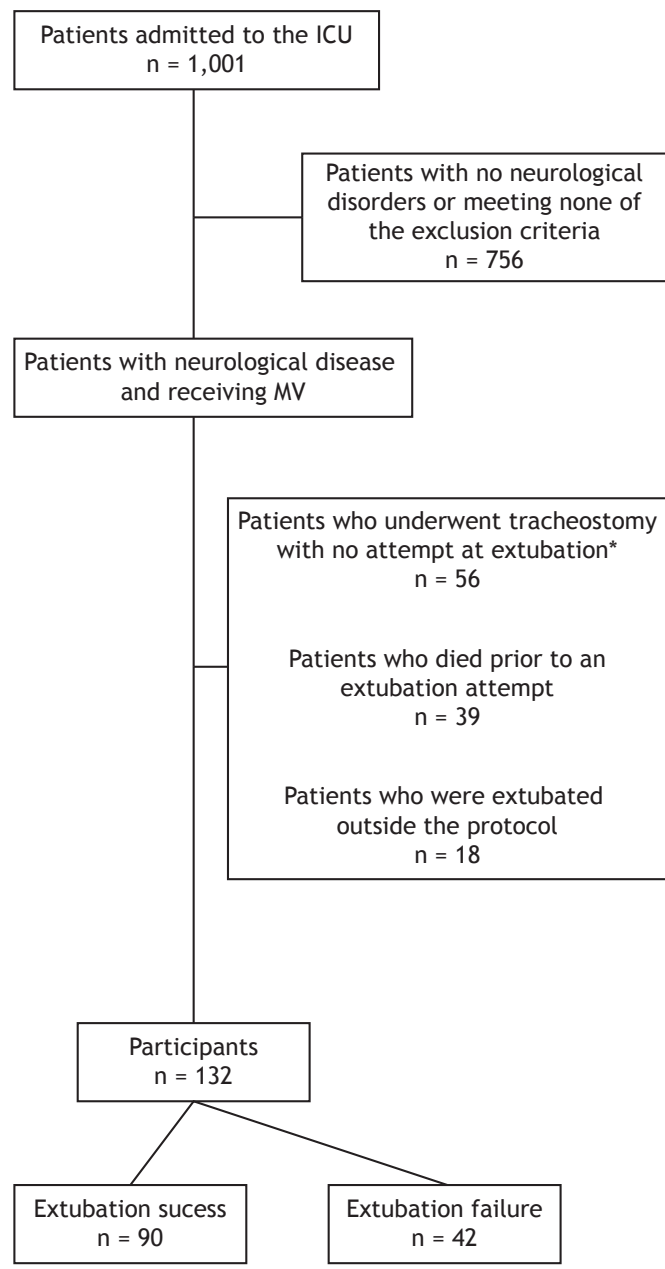

Figure 1. Schematic diagram of patient selection. MV: mechanical ventilation. *Patients with a Glasgow Coma Scale score of $<8$.
Scale (GCS) score $\geq 8$; normal acid-base balance; and normal electrolyte balance. ${ }^{(13)}$ Patients who passed a spontaneous breathing trial (SBT) were extubated. The criteria for a failed SBT were as follows: $\mathrm{SaO}_{2}$ < 90\%; RR > 35 breaths/min; HR > 130 bpm; a > $20 \%$ decrease or increase in systolic or diastolic blood pressure; diaphoresis; and psychomotor agitation. ${ }^{(14)}$ All SBTs were performed with a T-piece, supplemental oxygen, and an $\mathrm{FiO}_{2} \leq$ 0.4 for 30-120 min.

Before weaning, MEP and MIP were measured with a digital manometer (MVD-500, version 1.1; Globalmed, Porto Alegre, Brazil), being defined as the most positive and negative values, respectively, produced by three consecutive respiratory efforts against a unidirectional valve after $30 \mathrm{~s}$ of occlusion. All results were recorded on a data collection sheet. The frequency-to-tidal volume ratio $\left(f / V_{T}\right)$, minute volume, and $R R$ were measured with a spirometer attached to the endotracheal tube (model RM 121; Datex-Ohmeda, Inc., Madison, WI, USA). The GCS score was obtained immediately before the SBT. Given that intubated patients are unable to speak, their verbal response score is 1 (no response). The best motor response was defined as the ability to grasp and release the hand of the examiner on command twice consecutively, a score of 6 indicating the presence of motor response and a score of $<6$ indicating the absence of motor response. In addition, all patients underwent a tongue protrusion test of motor function consisting of sticking out their tongue on command. For patients who were unresponsive to verbal commands, the examiner demonstrated tongue protrusion.

For each patient, information was collected on the following: demographic characteristics; diagnosis at ICU admission; GCS scores at admission and at extubation; Acute Physiology and Chronic Health Evaluation II (APACHE II) score; length of ICU stay (in days); duration of mechanical ventilation (in days); cardiorespiratory variables after 30 or 120 min of spontaneous breathing; and incidence of ventilator-associated pneumonia.

Extubation failure was defined as the need for reintubation within $48 \mathrm{~h}$ of extubation. All of the patients who were successfully extubated were monitored throughout their hospital stay (until discharge) for complications requiring reintubation or tracheostomy, as well as for pneumonia and death. The diagnosis of pneumonia was established by a staff physician and was based on the criteria established by the local department of infection control, in accordance with the Brazilian National Health Surveillance Agency criteria and the American Thoracic Society guidelines for the management of adults with ventilator-associated pneumonia. ${ }^{(15,16)}$

Continuous variables were expressed as mean and standard deviation or median and interquartile range, whereas categorical variables were expressed as absolute numbers and proportions. Comparisons between groups at baseline were performed with the Student's t-test or the Mann-Whitney $U$ test for continuous variables and the chi-square test or 
Fisher's exact test for categorical variables. When necessary, the chi-square test was followed by analysis of adjusted residuals. The primary outcome measure was extubation failure or success. The relative risk was calculated as a measure of strength of association between predictive variables and the binary outcomes of interest. Sensitivity, specificity, and likelihood ratios for predicting extubation failure were also calculated. Variables with a value of $p<0.2$ were included in a Poisson regression model in order to compare extubation success and failure rates. Data were analyzed with the Statistical Package for the Social Sciences, version 18.0 (SPSS Inc., Chicago, IL, USA). The significance level was set at $p<0.05$.

\section{RESULTS}

A total of 132 patients were included in the analysis. The demographic characteristics, ventilator settings, and clinical parameters are described in Table 1. Mean patient age was $47.8 \pm 17.1$ years, and $71.2 \%$ were male. Mean APACHE II score was $18.8 \pm 5.41$. Median duration of mechanical ventilation was 8 days (interquartile range, 3-11.7 days). As can be seen in Table 1 , the most common reasons for ICU admission and orotracheal intubation were traumatic brain injury ( $n=62$ ), subarachnoid hemorrhage ( $n$ $=15$ ), postoperative complications of tumor surgery $(n=8)$, and hemorrhagic stroke $(n=43)$.

Of the 132 patients included in the analysis, 42 $(31.8 \%)$ failed extubation and were reintubated within
$48 \mathrm{~h}$. When the patients were grouped by GCS score, failure rates were $57.8 \%$ in the $8-9$ group and $15.7 \%$ in the $10-11$ group $(p<0.001)$. Attempts at extubation failed because of a change in the level of consciousness (in 7\%), accumulation of bronchial secretions (in $31 \%$ ), and inability to maintain airway patency (in $62 \%)$. A second attempt at extubation was made in $10(23.8 \%)$ of the 42 patients who failed extubation, $30(71.43 \%)$ of whom underwent tracheostomy and 2 of whom $(4.76 \%)$ died.

No significant differences were found between the successful extubation group and the failed extubation group regarding hemodynamic variables and arterial blood gases at extubation. The length of ICU stay, the length of hospital stay, and ICU outcomes were significantly different between the successful extubation group and the failed extubation group, as was the incidence of ventilator-associated pneumonia (Table 2).

As can be seen in Table 3, there were statistically significant differences between the successful extubation group and the failed extubation group regarding the ability to respond to commands, as assessed by GCS scores and the tongue protrusion test of motor function $(p<0.001)$. The patients who were unable to stick out their tongue on command were nine times as likely to fail extubation as were those who were able to do that (relative risk $=9.5 ; 95 \% \mathrm{CI}: 3.59-25.1 ; \mathrm{p}$ $<0.001$ ). Motor response as assessed by GCS scores also showed a high relative risk coefficient, and the patients who were unable to grasp the hand of the

Table 1. Demographic characteristics, ventilator settings, and clinical parameters in a sample of 132 mechanically ventilated patients in the ICU. ${ }^{\text {a }}$

\begin{tabular}{|c|c|c|c|c|}
\hline Variable & $\begin{array}{c}\text { Total } \\
\text { (n }=132)\end{array}$ & $\begin{array}{l}\text { Extubation success } \\
\qquad(\mathrm{n}=90)\end{array}$ & $\begin{array}{l}\text { Extubation failure } \\
\qquad(n=42)\end{array}$ & p \\
\hline Age, years & $47.8 \pm 17.01$ & $47.7 \pm 17.2$ & $48.2 \pm 16.7$ & $0.875^{*}$ \\
\hline Male gender, n (\%) & $61(72.6)$ & $66(73.3)$ & $28(66.7)$ & $0.561^{\dagger}$ \\
\hline APACHE II score & $18.87 \pm 5.41$ & $18.2 \pm 5.7$ & $20.4 \pm 4.4$ & $0.024^{*}$ \\
\hline GCS score at admission & $7.77 \pm 2.14$ & $7.94 \pm 2.13$ & $7.40 \pm 2.16$ & $0.79^{*}$ \\
\hline GCS score at extubation & $9.66 \pm 1.29$ & $10.1 \pm 0.95$ & $8.81 \pm 0,52$ & $<0.001^{*}$ \\
\hline Reasons for ICU admission, n (\%) & & & & $0.073^{\dagger}$ \\
\hline SAH & $15(11.4)$ & $7(7.8)$ & $8(19)$ & \\
\hline $\mathrm{ICH}$ & $43(35.6)$ & $32(35.6)$ & $15(35.7)$ & \\
\hline $\mathrm{POC}$ of tumor surgery & $8(6.1)$ & $8(8.9)$ & $0(0.0)$ & \\
\hline TBI & $62(47)$ & $43(47.8)$ & $19(45.2)$ & \\
\hline PEEP, $\mathrm{cmH}_{2} \mathrm{O}$ & $5.27 \pm 0.46$ & $5.25 \pm 0.45$ & $5.31 \pm 0.47$ & 0.516 \\
\hline $\mathrm{FiO}_{2}, \%$ & $34 \pm 0.49$ & $34 \pm 0.41$ & $34 \pm 0.63$ & $0.921^{*}$ \\
\hline $\mathrm{V}_{\mathrm{T}}, \mathrm{mL}$ & $522 \pm 134$ & $533 \pm 139$ & $499 \pm 122$ & $0.180^{*}$ \\
\hline MV, days ${ }^{b}$ & $8.0(3-11.75)$ & $6(3-10)$ & $11(6-14)$ & $<0.001^{\ddagger}$ \\
\hline PSV & $3.57 \pm 3.17$ & $2.81 \pm 2.32$ & $5.21 \pm 4.06$ & $<0.001^{*}$ \\
\hline PCV & $4.80 \pm 3.62$ & $4.38 \pm 3.64$ & $5.69 \pm 3.46$ & 0.055 \\
\hline MIP, $\mathrm{CmH}_{2} \mathrm{O}^{\mathrm{b}}$ & $65.5(46-83)$ & $70(52-87)$ & $48(37-67)$ & $<0.001^{\ddagger}$ \\
\hline MEP, $\mathrm{cmH}_{2} \mathrm{O}^{\mathrm{b}}$ & 59 (44-75) & $63(48-83)$ & $50(41-65)$ & $0.006^{\ddagger}$ \\
\hline $\mathrm{f} / \mathrm{V}_{\mathrm{T}}$, breaths $/ \mathrm{min} / \mathrm{L}^{\mathrm{b}}$ & $45(34-56)$ & $43(31-53)$ & $52.5(38.8-58)$ & $0.038^{\ddagger}$ \\
\hline
\end{tabular}

APACHE II: Acute Physiology and Chronic Health Evaluation II; GCS: Glasgow Coma Scale; SAH: subarachnoid hemorrhage; ICH: intracerebral hemorrhage; POC: postoperative complication; TBI: traumatic brain injury; PEEP: positive end-expiratory pressure; $\mathrm{V}_{\mathrm{T}}$ : tidal volume; $\mathrm{MV}$ : mechanical ventilation; PSV: pressure support ventilation; PCV: pressure-controlled ventilation; and $\mathrm{f} / \mathrm{V}_{\mathrm{T}}$ : frequency-to-tidal volume ratio. avalues expressed as mean $\pm \mathrm{SD}$, except where otherwise indicated. 'Values expressed as median (interquartile range). *Student's t-test. 'Pearson's chi-square test. "Mann-Whitney $\mathrm{U}$ test. 
examiner on command were three times as likely to fail extubation as were those who were able to do that (relative risk $=3.38 ; 95 \% \mathrm{CI}: 2.07-5.53 ; \mathrm{p}<0.001$ ).

The likelihood ratios for predicting extubation failure were 2.06 for a motor score of $<6$ and 7.35 for the inability to stick out the tongue (Table 4). A likelihood ratio $>1$ indicated a progressively higher probability of extubation failure, a motor score of $<6$ indicated a lower probability of extubation failure, and the inability to stick out the tongue on command indicated a moderate probability of extubation failure, being a more specific variable for risk prediction. After a Poisson regression multivariate analysis, only a motor score of $<6$ (relative risk $=1.57 ; 95 \% \mathrm{CI}: 1.01-2.44 ; \mathrm{p}=0.045)$ and the inability to protrude the tongue on command (relative risk $=6.84 ; 95 \% \mathrm{CI}: 2.49-18.8 ; \mathrm{p}<0.001$ ) remained significantly associated with extubation failure.

\section{DISCUSSION}

In ICU patients receiving mechanical ventilation, evaluation of predictors of extubation outcome is an important step in the weaning process. ${ }^{(3)}$ However, in the neurocritical care setting, the most widely used weaning and extubation parameters are not accurate enough to predict the risk of extubation failure. ${ }^{(6,7,11,17)}$ Evidence-based guidelines recommend that extubation be considered after reversal of the underlying cause of respiratory failure. ${ }^{(13)}$ However, in patients with neurological injuries, motor and cognitive sequelae can considerably affect their ability to protect the airway, regardless of their ability to maintain spontaneous ventilation. ${ }^{(18)}$

Most studies investigating clinical or mixed populations have reported mean extubation failure rates ranging from $15 \%$ to $25 \% .(4,19,20)$ The extubation failure rate in our study was $31.2 \%$, which is similar to those reported by Vallverdú et al. (i.e., 35\%) ${ }^{(9)}$ and Namen et al. (i.e., $38 \%)^{(21)}$ but higher than those found in populations with a similar profile (i.e., approximately $17 \%){ }^{(6,11,22)}$ Extubation failure rates vary across studies examining weaning and extubation in critically ill neurological patients in whom neurological injury constituted the primary cause of respiratory failure and who were considered for weaning on the basis of predictors established for the general population. This variability reinforces the need for evaluation criteria to define the parameters that are associated with the risk of extubation failure. In our study, extubation failure was found to be associated with a longer ICU stay, a longer hospital stay, a higher incidence of ventilator-associated pneumonia, and a higher mortality rate, a finding that is consistent with those of previous studies. $(1,19,22-25)$

In the present study, there were significant differences between the successful extubation group and the failed extubation group regarding APACHE II scores, MIP values, MEP values, and the rapid shallow breathing index, which was used in order to assess $\mathrm{f} / \mathrm{V}_{\mathrm{T}}$. However, when $f / V_{T}$ and the aforementioned variables were included in the logistic regression model, they were found to be inaccurate in predicting the risk of extubation failure in our population of neurological patients.

Our findings show that, in a population of patients with acute neurological disease, the inability to respond to commands is significantly associated with the probability of extubation failure. In addition, the inability to protrude the tongue, regardless of whether or not the patient was able to grasp the hand of the examiner on command (limb motor response), was associated with a high risk of extubation failure, being an independent predictor of extubation failure.

Although a GCS cut-off score of 8 has been used for risk assessment, verbal response cannot be reliably assessed when an artificial airway is present. ${ }^{(26,27)}$ In this sense, our findings support the concern that a cut-off score $\geq 8$ might not be a reliable parameter, given that mathematical combinations can result in a score of 8 even when the patient is unable to respond to commands. ${ }^{(4-6)}$

In a prospective observational cohort study of 122 patients, Mokhlesi et al. ${ }^{(28)}$ found that a GCS score of <

Table 2. Extubation outcomes. ${ }^{a}$

\begin{tabular}{|c|c|c|c|}
\hline Variable & $\begin{array}{l}\text { Success } \\
(n=90)\end{array}$ & $\begin{array}{c}\text { Failure } \\
(n=42)\end{array}$ & $\mathbf{p}$ \\
\hline Length of ICU stay, days & $12(7-17)$ & $17(14-23)$ & $<0.001^{*}$ \\
\hline Length of hospital stay, days & $25(17-30)$ & $30(21-51)$ & $0.009^{*}$ \\
\hline ICU outcome ${ }^{b}$ & & & $0.017^{\dagger}$ \\
\hline Discharge & $84(93.3)$ & $36(85.7)$ & \\
\hline Death & $1(1.1)$ & $5(11.9)^{\ddagger}$ & \\
\hline Transfer to another hospital & $5(5.6)$ & $1(2.4)$ & \\
\hline Hospital outcome ${ }^{\mathrm{b}}$ & & & $0.015^{\dagger}$ \\
\hline Discharge & 77 (85.6) & $28(66.7)$ & \\
\hline Death & $4(4.4)$ & $8(19)^{\ddagger}$ & \\
\hline Transfer to another hospital & $9(10)$ & $6(14.3)$ & \\
\hline VAPb & $31(34.4)$ & $23(54.8)$ & $0.027^{\dagger}$ \\
\hline
\end{tabular}

VAP: ventilator-associated pneumonia. ${ }^{a}$ Values expressed as median (interquartile range), except where otherwise indicated. 'Values expressed as $\mathrm{n}(\%)$. *Mann-Whitney $\mathrm{U}$ test. 'Pearson's chi-square test. ${ }^{\ddagger}$ Analysis of adjusted residuals revealed a statistically significant association (level of significance, 5\%). Length of ICU stay, length of hospital stay, mortality, and VAP incidence were significantly higher in the extubation failure group. 
Table 3. Motor variables, by extubation outcome. ${ }^{\mathrm{a}}$

\begin{tabular}{|c|c|c|c|}
\hline Variable & $\begin{array}{l}\text { Success } \\
(n=90)\end{array}$ & $\begin{array}{c}\text { Failure } \\
(n=42)\end{array}$ & p* \\
\hline $\begin{array}{l}\text { Best motor response } \\
\text { (hand grasping) }\end{array}$ & & & $<0.001$ \\
\hline < 6 (unable to respond) & $15(16.7)$ & $25(59.5)$ & \\
\hline$=6$ (able to respond) & $75(83.3)$ & $17(40.5)$ & \\
\hline Laterality of motor response & & & 0.132 \\
\hline Bilateral & $39(43.3)$ & $10(25)$ & \\
\hline Right & $29(32.2)$ & $18(45)$ & \\
\hline Left & $22(24.4)$ & $12(30)$ & \\
\hline Eye opening response & & & $<0.001$ \\
\hline 4- spontaneous & $41(45.6)$ & $14(33.3)$ & \\
\hline 3- to speech & $37(41.1)^{\dagger}$ & $8(19)$ & \\
\hline 2- to pain & $9(10)$ & $17(40.5)$ & \\
\hline 1- no response & $3(3.3)$ & $3(7.1)$ & \\
\hline Tongue protrusion test & & & $<0.001$ \\
\hline Positive & $62(68.9)$ & $4(9.5)$ & \\
\hline Negative & $28(31.1)$ & $38(90.5)$ & \\
\hline
\end{tabular}

avalues expressed as n (\%). *Pearson's chi-square test. ${ }^{\dagger}$ Analysis of adjusted residuals revealed a statistically significant association (level of significance, $5 \%$ ).

Table 4. Variables predictive of extubation failure, after Poisson correction.

\begin{tabular}{lcccc}
\multicolumn{1}{c}{ Variable } & Sensitivity, \% & Specificity, \% & Likelihood ratio & $\begin{array}{c}\text { Relative risk (95\% } \\
\text { CI) }\end{array}$ \\
$\begin{array}{l}\text { Best motor response } \\
<6^{*}\end{array}$ & 83.3 & 59.5 & 2.06 & $1.57(1.01-2.44)$ \\
$\begin{array}{l}\text { Tongue protrusion test } \\
\text { Negative }\end{array}$ & 68.9 & 90.5 & 7.35 & $6.84(2.49-18.8)$ \\
\hline
\end{tabular}

*The best motor response was defined as the ability to grasp and release the hand of the examiner on command twice consecutively, a score of 6 indicating the presence of motor response and a score of $<6$ indicating the absence of motor response. A likelihood ratio $>1$ indicates a high probability of extubation failure, a motor score of $<6$ indicates a low probability of extubation failure, and a negative tongue protrusion test indicates a moderate probability of extubation failure.

10 was a predictor of extubation failure. Vidotto et al. ${ }^{(7)}$ prospectively evaluated 92 patients who had undergone elective craniotomy and found that reintubation was required in $12 \%$ of those with a GCS score of $10-11$ and in $56 \%$ of those with a GCS score of $8-9$. These rates are very similar to the extubation failure rates found in the present study for GCS scores of 8-9 and 10-11 (i.e., $15.7 \%$ and $57.8 \%$, respectively). In contrast, Coplin et al.,(22) evaluating the implications of extubation delay in a cohort of 136 brain-injured patients, found a success rate of $80 \%$ for patients with a GCS score $\leq 8$ and a success rate of $91 \%$ ( 10 out of 11 patients) for patients with a GCS score $\leq 4$, with a significant increase in the incidence of pneumonia, length of ICU stay, and length of hospital stay in patients whose extubation was delayed on the basis of assessment of neurological function. We agree that delayed extubation in patients capable of spontaneous breathing and airway protection increases the risk of infections and the costs of care. However, our findings show that there is an increased risk of extubation failure in patients who are unable to perform simple motor tasks on command.

Salam et al. ${ }^{(4)}$ evaluated the ability of 88 clinical patients who had passed an SBT to complete four simple tasks (open eyes, follow with eyes, grasp hand, stick out tongue) before extubation and found that those who were unable to complete all four tasks were four times as likely to require reintubation as were those who completed the four tasks. Frutos-Vivar et al.,(20) in a prospective study evaluating the mental status of 900 patients immediately prior to extubation, subjectively defined (by the ability of patients to cooperate) as poor, moderate, or excellent, found no statistically significant difference in poor patient cooperation between patients who were reintubated and those who were not (39\% vs. $32 \%$ ). However, because the ability of patients to cooperate was subjectively evaluated, the methods cannot be reliably reproduced.

In the present study, the ability of patients to respond to commands was determined on the basis of their GCS motor response scores (i.e., their ability to grasp the hand of the examiner) and their ability to protrude their tongue on command. In patients whose motor score was $<6$, the extubation failure rate was $59.6 \%$; in those who were unable to stick out their tongue on command, the extubation failure rate was $90.5 \%$. These findings support concerns about assessing patient mental status with the GCS, given 
that all of the patients included in the study had GCS scores $\geq 8$. $^{(4-6)}$

According to Stocchetti et al., ${ }^{(18)}$ neurological patients commonly have cranial nerve deficits and are unable to protect their airway. In cases of traumatic brain injury, subarachnoid hemorrhage, intracerebral hemorrhage, and posterior fossa surgery, as well as in many other neurological disorders, the inability to swallow and to clear airway secretions has a considerable impact on the ability of patients to breathe without assistance, and a simple inspection of the tongue, both at rest and protruded, can aid in identifying cases of loss of airway protective reflexes. However, bedside assessment of tongue protrusion might not be sufficient to determine the risk of dysphagia or aspiration, which can only be assessed by videofluoroscopy. Nevertheless, it is not feasible to perform videofluoroscopy in orotracheally intubated patients, and the findings of the present study show that the inability to stick out the tongue on command is associated with a moderate risk of extubation failure.

Anderson et al. ${ }^{(6)}$ evaluated neurological assessment variables and extubation outcomes in patients in a neurocritical care unit and found that the presence of an endotracheal tube, fastening tape, and orolingual edema can prevent patients from protruding their tongue on command and therefore excluded this parameter from their analysis of 378 weaning and extubation processes. In the presence of edema-or if the presence of an endotracheal tube is a major factor limiting tongue protrusion-airway patency and the ability to protect the airway might be impaired, and this impairment has an impact on extubation outcomes. In our study, multivariate regression analysis showed that the inability to protect the airway was significantly associated with extubation failure.

According to Anderson et al., ${ }^{(6)}$ the type of command used is an essential component of the assessment process; eye opening to verbal command and following the examiner with the eyes might be excitatory responses to stimuli rather than volitional events, whereas grasping the hand of the examiner might be a primitive reflex, therefore being inaccurate in evaluating the ability of patients to respond to commands. The ability of patients to perform a simple motor task (i.e., hand grasping) is routinely evaluated in the ICU and was used in our study in order to differentiate between a reflex response and the ability to respond to commands, the test being considered positive when patients were able to grasp and release the hand of the examiner on command twice consecutively.

The inability to follow simple motor commands is predictive of extubation failure in critically ill neurological patients. The best motor response scores on the GCS and a simple bedside assessment of the ability of patients to protrude their tongue can inform clinical decisions regarding extubation. If our results are confirmed in other studies, the aforementioned parameters might be used as quick and easy screening tests to identify critically ill neurological patients who can be successfully extubated.

\section{REFERENCES}

1. Epstein SK. Decision to extubate. Intensive Care Med 2002;28(5):535 46. https://doi.org/10.1007/s00134-002-1268-8

2. Tanios MA, Nevins ML, Hendra KP, Cardinal P, Allan JE, Naumova EN et al: A randomized, controlled trial of the role of weaning predictors in clinical decision making. Crit Care Med. 2006;34(10):2530-5. https://doi.org/10.1097/01.CCM.0000236546.98861.25

3. Tobin MJ. The new irrationalism in weaning. J Bras Pneumol 2011;37(5):571-3.

4. Salam A, Tilluckdharry L, Amoateng-Adjepong Y, Manthous CA Neurologic status, cough, secretions and extubation outcomes. Intensive Care Med. 2004;30(7):1334-9. https://doi.org/10.1007/ s00134-004-2231-7

5. King CS, Moores LK, Epstein SK. Should patients be able to follow commands prior to extubation? Respir Care. 2010;55(1):56-65.

6. Anderson CD, Bartscher JF, Scripko PD, Biffi A, Chase D, Guanci $\mathrm{M}$, et al. Neurologic examination and extubation outcome in the neurocritical care unit. Neurocrit Care. 2011;15(3):490-7. https://doi. org/10.1007/s12028-010-9369-7

7. Vidotto MC, Sogame LC, Calciolari CC, Nascimento OA, Jardim JR The prediction of extubation success of postoperative neurosurgical patients using frequency-tidal volume ratios. Neurocrit Care. 2008;9(1):83-9. https://doi.org/10.1007/s12028-008-9059-x

8. Meade M, Guyatt G, Cook D, Griffith L, Sinuff T, Kergl C, et al Predicting success in weaning from mechanical ventilation. Chest 2001;120(6 Suppl):400S-24S. https://doi.org/10.1378/chest.120.6_ suppl.400S

9. Vallverdú I, Calaf N, Subirana M, Net A, Benito S, Mancebo J. Clinical characteristics, respiratory functional parameters, and outcome of a two-hour T-piece trial in patients weaning from mechanical ventilation. Am J Respir Crit Care Med. 1998;158(6):1855-62. https:// doi.org/10.1164/ajrccm.158.6.9712135

10. Nemer SN, Barbas CS. Predictive parameters for weaning from mechanical ventilation. J Bras Pneumol. 2011;37(5):669-79. https://

doi.org/10.1590/S1806-37132011000500016

11. Ko R, Ramos L, Chalela JA. Conventional weaning parameters do not predict extubation failure in neurocritical care patients. Neurocrit Care. 2009;10(3):269-73. https://doi.org/10.1007/s12028-008-9181-9

12. Stevens RD, Lazaridis C, Chalela JA. The role of mechanica ventilation in acute brain injury. Neurol Clin. 2008;26(2):543-63, x. https://doi.org/10.1016/j.ncl.2008.03.014

13. Maclntyre NR, Cook DJ, Ely EW Jr, Epstein SK, Fink JB, Heffner $J E$, et al. Evidence-based guidelines for weaning and discontinuing ventilatory support: a collective task force facilitated by the American College of Chest Physicians; the American Association for Respiratory Care; and the American College of Critical Care Medicine. Chest. 2001;120(6 Suppl):375S-95S. https://doi.org/10.1378/chest.120.6 suppl.375S

14. Goldwasser R, Farias A, Freitas EE, Saddy F, Amado V, Okamoto V. Mechanical ventilation of weaning interruption [Article in Portuguese] J Bras Pneumol. 2007;33 Suppl 2S:S128-36. https://doi.org/10.1590/ S1806-37132007000800008

15. Brasil. Ministério da Saúde. Agência Nacional de Vigilância Sanitária [homepage on the Internet]. Brasilia: Ministério da Saúde [updated 2015 Aug 27; cited 2016 Oct 1]. Trato respiratório - Critérios Nacionais de Infecções relacionadas à Assistência à Saúde (Versão 1.1). [about 3 screens. Available from: http://portal.anvisa gov.br/resultado-de-busca?p_p_id=101\&p_p_lifecycle $=0 \&$ p_p_ state $=$ maximized $\& p \quad p$ mode $=v i e w \& p \_p$ col $i d=$ column $-1 \& p \_p$ col_count $=1 \&$ _101_struts_action $=\% 2$ Fasset_publisher $\% 2 F v i e w$ content\&_101_assetEntryld $=271693 \&$ 101_type=document $\&$ redirect $=$ http $\% 3 \mathrm{~A} \% 2 \mathrm{~F} \% 2 \mathrm{Fportal}$.anvisa.gov.br\%2Fresultadode-busca\%3Fp_p_id \% 3D3\% 26p_p_lifecycle \% 3D0\% 26p_p_ state \% 3D normal \% 26p_p_mode \% 3 Dview \% $26 p_{-} p_{\text {_ }}$ col_id\%3Dcolumn-1\%26p_p_col_count \%3D1\%26_3 groupld\%3D0\%26_3_keywords\%3DCrit \%25C3\%25A9rios\%2Bnac ionais \%2Bde\%2Binfec \% 25C3\%25A7\%25C3\%25B5es\%2Brelacio nadas $\% 2$ B $\% 25$ C3\%25A0\%2Bassist $\% 25$ C3\%25AAncia \%2B $\% 25 \mathrm{C}$ 
3\%25A0\%2Bsa\%25C3\%25BAde\%26_3_cur\%3D1\%26_3_struts_ action\%3D\%252Fsearch\%252Fsearch\%26_3_format\%3D\%26_3_ formDate\%3D1441824476958

16. American Thoracic Society; Infectious Diseases Society of America Guidelines for the management of adults with hospital-acquired, ventilator-associated, and healthcare-associated pneumonia. Am J Respir Crit Care Med. 2005;171(4):388-416. https://doi.org/10.1164/ rccm.200405-644ST

17. Wendell LC, Kofke WA. So you think you can safely extubate your patient? Neurocrit Care. 2011;15(1):1-3. https://doi.org/10.1007/ s12028-011-9558-z

18. Stocchetti N, Beretta L, Citerio G. Criteria for extubation in neurologic patients. Crit Care Med. 2009;37(4):1529; author reply 1529-30 https://doi.org/10.1097/CCM.0b013e31819d2e62

19. Savi A, Teixeira C, Silva JM, Borges LG, Pereira PA, Pinto KB, et al. Weaning predictors do not predict extubation failure in simpleto-wean patients. J Crit Care. 2012;27(2):221.e1-8. https://doi. org/10.1016/j.jcrc.2011.07.079

20. Frutos-Vivar F, Ferguson ND, Esteban A, Epstein SK, Arabi Y, Apezteguía $C$, et al. Risk factors for extubation failure in patients following a successful spontaneous breathing trial. Chest 2006;130(6):1664-71. https://doi.org/10.1378/chest.130.6.1664

21. Namen AM, Ely EW, Tatter SB, Case LD, Lucia MA, Smith A, et al. Predictors of successful extubation in neurosurgical patients. Am J Respir Crit Care Med. 2001;163(3 Pt 1):658-64. https://doi. org/10.1164/ajrccm.163.3.2003060
22. Coplin WM, Pierson DJ, Cooley KD, Newell DW, Rubenfeld GD. Implications of extubation delay in brain-injured patients meeting standard weaning criteria. Am J Respir Crit Care Med. 2000;161(5):1530-6. https://doi.org/10.1164/ajrccm.161.5.9905102

23. Epstein SK, Ciubotaru RL, Wong JB. Effect of failed extubation on the outcome of mechanical ventilation. Chest. 1997;112(1):186-92. https://doi.org/10.1378/chest.112.1.186

24. Frutos-Vivar F, Esteban A, Apezteguia C, González M, Arabi Y Restrepo MI, et al. Outcome of reintubated patients after scheduled extubation. J Crit Care. 2011;26(5):502-9. https://doi.org/10.1016/j. jcrc.2010.12.015

25. Tobin MJ, Jubran A. Variable performance of weaning-predictor tests: role of Bayes' theorem and spectrum and test-referral bias. Intensive Care Med. 2006;32(12):2002-12. https://doi.org/10.1007/ s00134-006-0439-4

26. Marion DW, Carlier PM. Problems with initial Glasgow Coma Scale assessment caused by prehospital treatment of patients with head injuries: results of a national survey. J Trauma. 1994;36(1):89-95. https://doi.org/10.1097/00005373-199401000-00014

27. Teasdale GM, Murray L. Revisiting the Glasgow Coma Scale and Coma Score. Intensive Care Med. 2000;26(2):153-4. https://doi org/10.1007/s001340050037

28. Mokhlesi B, Tulaimat A, Gluckman TJ, Wang Y, Evans AT, Corbridge TC. Predicting extubation failure after successful completion of a spontaneous breathing trial. Respir Care. 2007;52(12):1710-7. 